\title{
Oceanography
}

CITATION

Ricciardi, L., V. Williamson Whitney, and A. Johnson. 2016. MS PHD'S: By and for minorities. Oceanography 29(1):58-59, http://dx.doi.org/10.5670/oceanog.2016.13.

DOI

http://dx.doi.org/10.5670/oceanog.2016.13

COPYRIGHT

This article has been published in Oceanography, Volume 29, Number 1, a quarterly journal of The Oceanography Society. Copyright 2016 by The Oceanography Society. All rights reserved.

USAGE

Permission is granted to copy this article for use in teaching and research. Republication, systematic reproduction, or collective redistribution of any portion of this article by photocopy machine, reposting, or other means is permitted only with the approval of The Oceanography Society. Send all correspondence to: info@tos.org or The Oceanography Society, PO Box 1931, Rockville, MD 20849-1931, USA. 


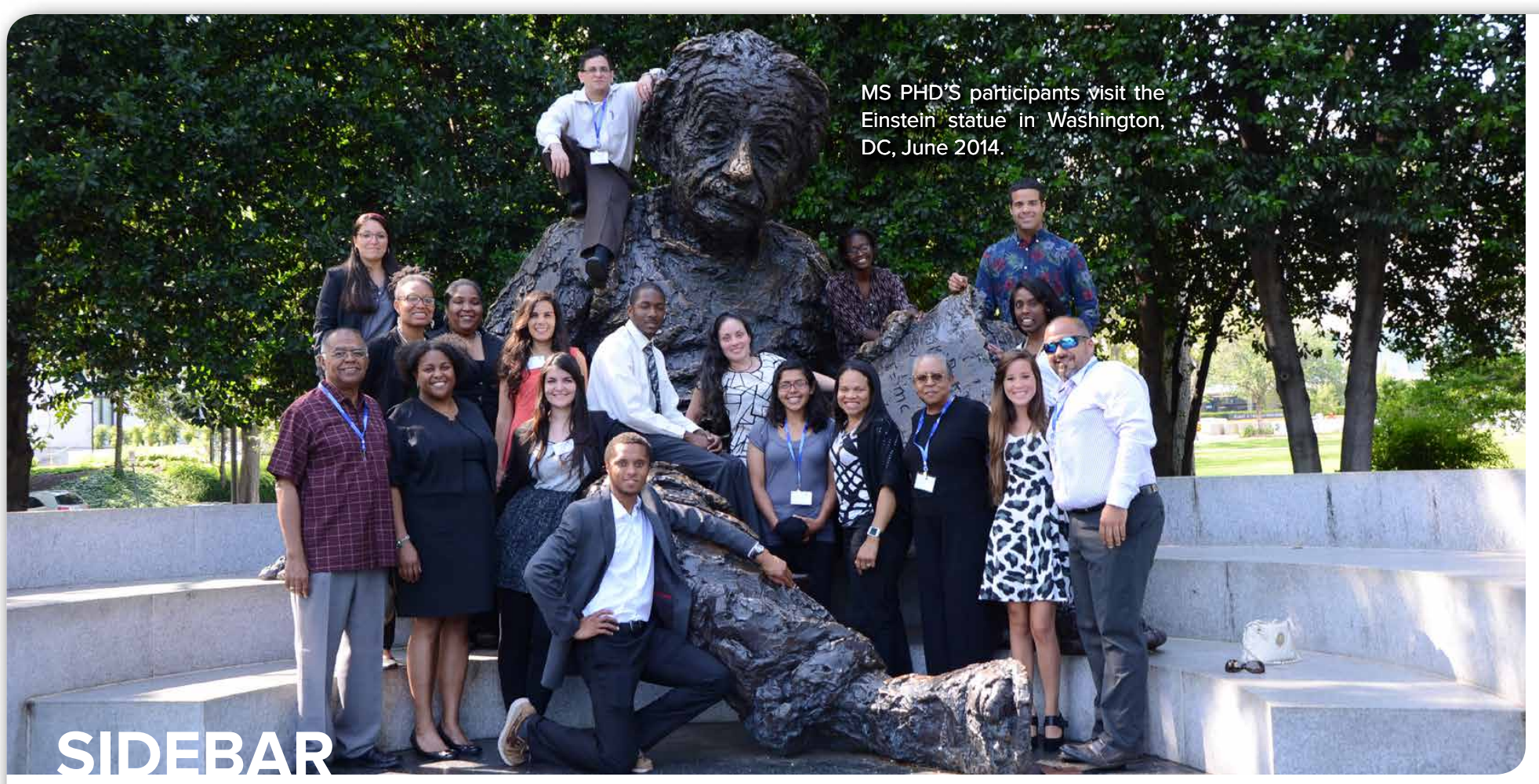

\section{MS PHD'S: By and for Minorities}

By Lois Ricciardi, Vivian Williamson Whitney, and Ashanti Johnson

The Minorities Striving and Pursuing Higher Degrees of Success in Earth System Science (MS PHD'S) professional development program was founded in 2003 upon a vision that underrepresented minority (URM) populations can and should play a role in facilitating a network to attract, retain, and increase the number of URMs in the Earth System Science (ESS) workforce. The pilot MS PHD'S program focused on effective mentoring and professional development administered by and for minorities. These activities are designed to:

- Increase exposure to and engagement in the ESS community via participation in scientific conferences, mentoring relationships, virtual activities, and field trips

- Enhance professional skills, grantsmanship, oral and written communication

- Provide resources regarding future funding, education, and career opportunities

- Facilitate networking opportunities with established researchers and educators

- Sustain ongoing interaction, communication, and support via membership within a virtual community composed of peers, junior/ senior-level researchers, and educators actively involved in facilitating full participation of minorities in ESS

Since 2003, the program has grown to serve an impressive number of alumni who, in addition to establishing careers within the ESS workforce, also return to mentor the next generation of URM scientists. Alumni, mentors, and current participants partake in a threepart program that provides continuity of supportive mentoring and training networks via an active virtual community.

Phase I programming is conducted during the American Geophysical Union (AGU) Fall Meeting in San Francisco. Phase I facilitates student engagement through community building and professional development activities, including forming and maintaining effective mentee/mentor partnerships, honing oral and written presentation skills, creating compelling CVs, networking, and career planning/goal setting.

During Phase II, in conjunction with MS PHD'S Organizational Partners (MS PHD'S OPS), students attend discipline-specific meetings and conferences aligned with their interests. Meeting mentors provide one-on-one or small group interaction with students during these meetings. Since 2004, 19 MS PHD'S OP scientific societies have provided URM students with opportunities to engage in organization-specific programs and broaden their exposure to ESS by offering travel support, research presentation opportunities, and mentoring experiences at their conferences. Feedback from MS PHD'S OPs emphasizes that MS PHD'S students have communicated their science effectively, been fully engaged in the MS PHD'S OPs student activities, and overall have greatly enhanced MS PHD'S OPs broadening participation activities at their meetings by participating in panels and workshops.

Phase III programming occurs in March in Washington, DC, and serves as a reunion of the cohort, with a capstone event hosted by the National Academy of Sciences. Mentees tour federal agencies where they learn about career, funding, research, and internship opportunities and hear presentations from and network with program directors and agency representatives. They also gain exposure to the legislative system and learn how it impacts funding for professional development programs for URMs in ESS fields. Participants fine-tune professional skills through in-house workshops focusing on $\mathrm{CV} /$ résumé development, oral and poster presentations, career goals, and post-graduation planning. Additionally, participants present their research during a poster session at the National Science Foundation (NSF) that is well attended by representatives from the federal, state, and private sectors. At the conclusion of Phase III programming, each student receives a fellowship of up to $\$ 1,000$ and designation of "MS PHD'S Fellow." 
Since 2003, MS PHD'S has also maintained a three-part team mentoring structure in which student interaction with multiple mentors results in exposure to diverse learning perspectives and increases one-on-one, mentee/mentor interaction.

Program Mentors are successful URM scientist role models who participate in all Phase I and III activities with the cohort. Upon conclusion of program activities, Program Mentors continue offering ad hoc assistance to mentees by sharing opportunities such as internships or fellowships; providing feedback regarding mentees' academic, research, and professional activities; and/or reviewing mentees' fellowship applications, proposals, manuscripts, and other academic and career pursuits. Since 2003, 20 URM scientists have served as Program Mentors. Ten Program Mentors have progressed from mentee to mentor during the program.

Meeting Mentors are volunteer URM and non-URM scientists who are recruited to participate in either Phase I or Phase II activities. These individuals have a desire to mentor URM students and support broadening participation within their academic and research programs. These partnerships are created based on common scientific interests and expectations. Meeting Mentors help students navigate meeting activities, attend sessions together and debrief afterward, facilitate networking by introducing mentees to colleagues, and advise mentees on academic and career goals.

Dream Team “Near-Peer” Mentors are selected from MS PHD'S alumni by a competitive application process. The Dream Team engages with the newest cohort by providing peer mentoring to new students and supporting staff and Program Mentors with programmatic activities. Leadership experiences gained as Dream Team members focus on the importance of understanding the process of transitioning from participant to leader and from mentee to mentor, and serve to further prepare alumni for becoming future ESS leaders.

MS PHD'S emphasizes face-to-face community-building activities during Phases I and III. These activities facilitate bonding and support between participants who also gain exposure to science and networking through field trips to places such as California Academy of Sciences, Aquarium of the Bay, and Smithsonian museums (see photo). Participants plan and conduct a multicultural food festival where each participant prepares a favorite dish representative of his or her culture. Participants also engage in two closed discussion groups-the men's Our Voices: Affirming and Empowering Brothers and Women's Talking Circle-where they share their most private challenges, obstacles, and fears, and counsel each other on strategies to overcome these hurdles.

MS PHD'S professional development experiences give students the skills they need to develop professional relationships with advisors and colleagues, and develop self-efficacy and confidence. In addition to participation in conference and professional society events, students also engage in activities facilitated by the program's professional development consultant, program mentors, and program staff. These activities include developing a professional Web profile, refining oral and written presentation skills, and assembling a short-, mid-, and long-term career development plan.

To expand the MS PHD'S experience beyond the Phase I, II, and III meetings for participants geographically dispersed throughout the United States and Puerto Rico, a listserv, website, online public profiles, closed Facebook groups, and video conferencing are used to develop and sustain mentorship and community. Members of the scientific community are invited to share information virtually regarding internships, opportunities to attend and present at conferences, fellowships, and related academic and professional information of interest to MS PHD'S participants.

Over the course of more than a decade and across 11 cohorts, MS PHD'S has promoted the advancement of 238 URM students and recent doctoral degree recipients committed to achieving outstanding ESS careers. Of the 238 alumni, 127 participants self-identified as African American; 49 as Puerto Rican; 29 as Hispanic/Mexican American; 16 as American Indian/Alaskan Native; eight as Native Hawaiian/Pacific Islander; nine as White/Caucasian, Other Hispanic, African, Asian or Multi-Ethnic; $61 \%$ as female and $39 \%$ as male. A total of 135 students began participation in MS PHD'S as graduate students, 95 as undergraduates, and the remaining eight as postbaccalaureate in transition to graduate school. To date, 62,21 , and 16 alumni have received doctoral, master's, and bachelor's degrees, respectively, and are currently employed within the geoscience and related industries workforce. Geographic representation of participants has included 39 states, the District of Columbia, Puerto Rico, and international postdoctoral appointments in Saudi Arabia and France.

Anonymous surveys completed annually by student participants show broad agreement (96\%) on the need for MS PHD'S as well as willingness to advocate for the program. At the conclusion of their MS PHD'S experience, students report that they are better prepared to achieve their academic and professional goals. Feedback from participants, mentors, sponsoring agencies/organizations, and guest panelists regarding the quality and effectiveness of and the need for the MS PHD'S has also been positive.

The MS PHD'S structure of mentoring, community building, networking, and professional development activities provides a sound framework for continuing to develop, foster, and expand an inclusive community prepared to excel in a global workforce. In 2011, in response to the expressed needs of MS PHD'S alumni, the MS PHD'S Beyond the PhD (MS PHD'S B-PhD) program was launched to facilitate the advancement of recent URM geoscience doctoral degree recipients in academic, federal government, and industry sectors. Most recently, MS PHD'S has served as the model for the pilot MS PHD'S-GEO REU professional development program designed specifically for URM undergraduates who participate in an NSF Research Experiences for Undergraduates (REU) program. Through the MS PHD'S virtual activities, the program plans to maintain continuity of its core mission beyond current program funding. MS PHD'S also continues to actively seek federal and private funding to support and sustain future generations of URM ESS scientists.

\section{MS PHD'S ORGANIZATIONAL PARTNERS}

American Geophysical Union, American Geosciences Institute, American Meteorological Society, Association for the Sciences of Limnology and Oceanography, Compact for Faculty Diversity Institute on Teaching and Mentoring, Consortium for Ocean Leadership, Digital Library for Earth System Science, Ecological Society of America, Ivy League Symposium, Geological Society of America, National Association of Black Geoscientists, National Association of Geoscience Teachers, National Science Teachers Association, National Technical Association, Ocean Carbon Biochemistry Science Program, On The Cutting Edge, Sigma Xi, Society for Freshwater Science, Society for Advancement of Chicanos and Native Americans in Science, and The Oceanography Society.

\section{AUTHORS}

Lois Ricciardi (Iricciardi@ibparticipation.org) is Human Resources Director and Project Manager, MS PHD'S, Institute for Broadening Participation, Damariscotta, ME, USA. Vivian Williamson Whitney is a Broadening Participation Specialist, Institute for Broadening Participation, Damariscotta, ME, USA, and a professional development consultant for MS PHD'S. Ashanti Johnson is Assistant Vice Provost for Faculty Recruitment and Associate Professor of Environmental Science, The University of Texas at Arlington, Arlington, TX, USA, and Executive Director, Institute for Broadening Participation, Damariscotta, ME, USA. As founder and director of MS PHD'S, Johnson received the Presidential Award for Excellence in Science, Mathematics, and Engineering Mentoring at a White House ceremony on January 6, 2010.

\section{ARTICLE CITATION}

Ricciardi, L., V. Williamson Whitney, and A. Johnson. 2016. MS PHD'S: By and for minorities. Oceanography 29(1):58-59, http://dx.doi.org/10.5670/oceanog.2016.13. 